\title{
TRABALHO E FORMAÇÃO DOCENTE PARA O ATENDIMENTO EDUCACIONAL ESPECIALIZADO
}

\author{
Eliane Brunetto PERTILE ${ }^{1}$ \\ Elisabeth ROSSETTO ${ }^{2}$
}

RESUMO: O presente artigo tem como objetivo apresentar resultados parciais de uma pesquisa documental e bibliográfica sobre o Atendimento Educacional Especializado (AEE) realizado na Sala de Recursos Multifuncional. Procuramos identificar as atribuições do professor do AEE e a formação direcionada a este profissional. A partir de 2008, este serviço é posto em evidência nas normativas e apresenta centralidade enquanto apoio para a inclusão dos alunos com deficiência no ensino regular. Consideramos que a formação direcionada ao professor, como forma de atualizá-lo ao trabalho no AEE, ainda é insuficiente. Além disso, constatamos que, assim como ocorre com os dos demais professores, a formação apresenta características que denotam superficialidade, com adesão à modalidade de ensino a distância. Tendo como parâmetro a Teoria Histórico-Cultural, compreendemos a relevância do investimento em uma formação consistente que instrumentalize o professor, ademais a partir deste referencial ressaltamos a relevância da ação docente, enquanto mediação para o processo de escolarização dos alunos.

PALAVRAS-CHAVE: Atendimento educacional especializado. Sala de recursos multifuncional. Atribuições do professor. Formação docente.

\section{INTRODUÇÃO}

O presente artigo tem como objetivo apresentar o resultado parcial de uma pesquisa documental e bibliográfica em nível de Mestrado - Especialização stricto sensu -, a qual tomou o trabalho docente no AEE da SRM como centralidade. Propomo-nos investigar quais as possíveis contribuições da ação pedagógica neste serviço para o processo de escolarização de alunos com deficiência. Para alcançar este objetivo compreendemos a relevância de identificar a formação direcionada aos professores e o trabalho educacional proposto.

\footnotetext{
${ }^{1}$ Doutoranda em Educação. UEM - Universidade Estadual de Maringá. Programa de Pós-Graduação em Educação. Mestre em Educação. UNIOESTE - Universidade Estadual do Oeste do Paraná. Professora da Secretaria de Estado da Educação do Paraná. Cascavel - PR - Brasil. 85812-150 elianebrunetto@gmail.com.

2 Professora efetiva. UNIOESTE - Universidade Estadual do Oeste do Paraná. Programa de PósGraduação em Educação. Doutora em Educação. UFRGS - Universidade Federal do Rio Grande do Sul. Cascavel - PR - Brasil. 85812-150 - erossetto2013@gmail.com.
} 
Em relação aos documentos, contemplamos publicações oficiais que repercutem na implantação do programa da SRM e na formação do professor para o trabalho no AEE. O estudo bibliográfico, por sua vez, tem como base teóricos que possibilitam o aprofundamento acerca da Teoria Histórico-Cultural. Selecionamos textos de Lev Semenovich Vigotski ${ }^{3}$ e de pesquisadores atuais que buscam interpretar a obra vigotskiana de forma articulada com as discussões contemporâneas.

\section{Trabalho e formação docente para o AEE}

O estudo acerca do processo educacional das pessoas com deficiência nos revela um quadro histórico de exclusão, com o predomínio de praticas segregativas como única possibilidade educativa. No entanto, a luta das pessoas com deficiência, bem como as políticas mais recentes, indicam a oportunidade de acesso a escolarização, dentre outros direitos sociais, de forma cada vez mais intensa. Constatamos, assim, que a crescente inclusão de alunos com deficiência no ensino regular é um processo recente, que tem se apresentado como assunto frequente nas discussões educacionais, tanto que uma das preocupações presentes no diálogo entre os educadores é o atendimento às necessidades dos seus alunos, pois exigem recursos diferenciados e uma organização distinta do ensino. Nesse contexto, a existência de programas de apoio e a disposição de determinadas condições nas escolas são colocadas em discussão.

Neste sentido, o AEE é uma temática em evidência no momento, pois se apresenta como um apoio significativo para as escolas regulares, tendo em vista o crescente número de alunos com deficiência que ingressam no ensino comum e a ênfase dada a este serviço principalmente após a instituição da Política Nacional de Educação Especial na Perspectiva da Educação Inclusiva de 2008 (BRASIL, 2008). Segundo esta normativa o AEE tem a função de “[...] identificar, elaborar, e organizar recursos pedagógicos e de acessibilidade, que eliminem as barreiras para a plena participação dos alunos, considerando suas necessidades específicas”. (BRASIL, 2008, p.8).

O AEE constitui-se com uma rede de serviços destinados ao público da educação especial, isto é, aos “[...] alunos com deficiência, transtornos globais de desenvolvimento e altas habilidades/superdotação" matriculados na rede regular

\footnotetext{
3 A grafia do nome do autor é utilizada com algumas variações (Vygotski, Vigostki, Vygotsky). Utilizaremos a forma apresentada, exceto em citações, situação em que manteremos o modo apresentado pelo autor referenciado.
} 
(BRASIL, 2008, p.7). Perpassa todos os níveis e modalidades de ensino em caráter complementar e/ou suplementar. Desta forma, traz uma nova abordagem para a educação especial em âmbito nacional, pois propõe significativas modificações para o atendimento ao alunado e destaca a responsabilidade do setor público sobre a educação das pessoas com deficiência.

A SRM, por sua vez, é um programa instituído a partir dos preceitos da Política Nacional de Educação Especial na Perspectiva da Educação Inclusiva (BRASIL, 2008). Disseminada nacionalmente, constitui-se como proposta oficial para o atendimento aos alunos da educação especial, sendo espaço prioritário para a realização do AEE.

Este programa assume uma responsabilidade significativa nas escolas regulares, pois é colocado como proposição central para apoio aos alunos com deficiência. Juntamente com a grande responsabilização das SRM, notamos, também, a ênfase na apresentação do professor do AEE como articulador da organização necessária para a escolarização de seus alunos.

A partir da Política Nacional (BRASIL, 2008), várias foram as normativas que indicaram o AEE na SRM e o caracterizaram como subsidiador para o processo inclusivo dos alunos da educação especial. O trabalho pedagógico e a especificidade da ação educacional nesse serviço, por sua vez, não se apresentaram claramente. O mesmo podemos considerar acerca da formação necessária ao professor do AEE.

Temos claro nos documentos que as atividades do AEE na SRM se diferenciam das realizadas nas salas de aula regular e que a proposta deste serviço deve se articular com a proposta do ensino comum. Procuramos, no entanto, a caracterização do trabalho pedagógico, compreendendo os fundamentos teóricos que dão suporte às ações do professor. Esta investigação, por sua vez, nos remete a formação docente destinada aos profissionais que devem trabalhar neste serviço.

A Resolução $n^{\circ}$ 4, de 2009, indica que “[...] para atuação no AEE, o professor deve ter formação inicial que o habilite para o exercício da docência e formação específica para a educação especial.” (BRASIL, 2009, p.3). Mas não há uma especificação acerca do conhecimento necessário ao professor do AEE com base no trabalho na SRM e nem a indicação de uma formação diferenciada daquela já existente.

Concomitante ao pouco direcionamento da formação para o professor do AEE, vemos uma intensa carga de responsabilidade direcionada a este profissional, a Resolução n $^{\circ}$, de 2009, estabelece no artigo 13 as atribuições, como segue: 
I - identificar, elaborar, produzir e organizar serviços, recursos pedagógicos, de acessibilidade e estratégias considerando as necessidades específicas dos alunos público-alvo da Educação Especial;

II - elaborar e executar plano de Atendimento Educacional Especializado, avaliando a funcionalidade e a aplicabilidade dos recursos pedagógicos e de acessibilidade;

III - organizar o tipo e o número de atendimentos aos alunos na sala de recursos multifuncionais;

IV - acompanhar a funcionalidade e a aplicabilidade dos recursos pedagógicos e de acessibilidade na sala de aula comum do ensino regular, bem como em outros ambientes da escola;

$\mathrm{V}$ - estabelecer parcerias com as áreas intersetoriais na elaboração de estratégias e na disponibilização de recursos de acessibilidade;

VI - orientar professores e famílias sobre os recursos pedagógicos e de acessibilidade utilizados pelo aluno;

VII - ensinar e usar a tecnologia assistiva de forma a ampliar habilidades funcionais dos alunos, promovendo autonomia e participação;

VIII - estabelecer articulação com os professores da sala de aula comum, visando à disponibilização dos serviços, dos recursos pedagógicos e de acessibilidade e das estratégias que promovem a participação dos alunos nas atividades escolares. (BRASIL, 2009, p.3).

Temos ainda outros documentos que apresentam as atribuições do professor, mas de modo geral é possível verificar uma ampla gama de tarefas. É previsto o trabalho direto com o aluno em período de contraturno; o trabalho colaborativo para subsidiar as ações e a formação do professor da sala regular; a elaboração de materiais específicos para uso dos alunos nas salas de aula; a orientação à família; e a articulação com setores e profissionais externos à escola que possam colaborar para o atendimento às necessidades especiais dos alunos.

Chama-nos atenção a responsabilização que é imputada a esse profissional que não se direciona apenas ao ensino, mas a várias atividades organizativas e articuladoras dentro do espaço escolar e, possivelmente, fora dele. Nesse sentido, por meio do programa da SRM, o mesmo professor pode trabalhar com várias áreas. No entanto, cada área tem um conhecimento específico e aprofundado. Assim, cabe a organização dos sistemas de ensino e a realização da formação constante para o professor.

De acordo com as normativas, o AEE deve ser disponibilizado na SRM para todo o público-alvo da educação especial que precisar do apoio. Coerente, com este propósito, em 2011, o Decreto $\mathrm{n}^{\mathrm{o}}$ 7.611, de 17 de novembro (BRASIL, 2011), estabelece o apoio técnico e financeiro da União “[...] para a formação continuada de 
professores, inclusive para o desenvolvimento da educação bilíngue para estudantes surdos ou com deficiência auditiva e do ensino do Braille para estudantes cegos ou com baixa visão".

Mas, em termos efetivos, paralela à constituição desse programa novo, denso em responsabilidades frente à inclusão dos alunos (principalmente com deficiência), falta o fornecimento de uma formação que proporcione um conhecimento diferenciado para o docente. De modo geral, não há a indicação de uma formação inicial distinta, nem de professores diferenciados daqueles que já vinham se dedicando à educação especial. Temos, então, docentes que, por vezes, tinham como base de trabalho outros princípios que não os da inclusão, agora imbuídos de um novo pensamento e de um fazer diferenciado, mas sem o direcionamento de uma formação que os respalde.

Nota-se que, a formação para o trabalho pedagógico para a SRM deu-se no curso da implantação do serviço, não ocorreu uma capacitação prévia. Neste processo, houve destaque, dentre as ações do MEC, para a formação a distância como forma de atualizar os professores às novas tarefas, constituindo-se uma formação emergencial e de grande abrangência.

Observamos que a educação a distância $(\mathrm{EaD})$ tem sido uma via muito utilizada não somente para o profissional que atua na SRM, mas para a formação dos docentes em geral. Além de cursos de formação continuada para o AEE, cursos de especialização - latu sensu - na modalidade EaD foram aprovados pelo MEC e tiveram grande abrangência em todo o país. O Departamento de Políticas de Educação Especial anunciou que somente no ano de 2010 foram envolvidos 11350 professores relativos ao edital de 2009 e mais 12000 professores já equivalentes aos cursos disponíveis na plataforma Freire.

Um olhar mais crítico revela que, embora os cursos a distância, on-line, pareçam uma estratégia convidativa e confortável, escondem uma formação docente limitada e aligeirada justificada pela urgência de formar o profissional para uma tarefa imediata. Dessa forma, o professor enfrenta o dilema de conduzir o processo de ensino/aprendizagem rumo à humanização ${ }^{4}$ dos alunos, quando sua própria formação é limitada.

$\mathrm{Na}$ modalidade $\mathrm{EaD}$, há uma ênfase na aprendizagem colaborativa entre os professores. Os fóruns de discussão são atividades comumente utilizadas e valorizam de

4 Utilizamos esse conceito fundamentados na obra de Leontiev (1978), na qual corresponde ao desenvolvimento das capacidades humanas. 
sobremaneira a fala cotidiana e as trocas de experiências, tendo como parâmetro a imediaticidade e o pragmatismo. O aprofundamento teórico não é centralidade nessa formação e, embora sejam utilizados textos e leituras, estes desaparecem em meio ao diálogo espontâneo.

Considerando o contexto histórico em que se dá a formação do professor para as práticas inclusivas, alerta-nos o fato de que nas últimas décadas retoma-se na formação da grande maioria dos docentes princípios pedagógicos associados ao "aprender a aprender" (DUARTE, 2006). Os professores, assim como os alunos, aprendem a aprender por meio de um sistema de formação massificado e superficial em que o conhecimento científico é secundarizado e o saber tácito do professor, em contrapartida, é excessivamente valorizado.

Esta limitação pragmática repercute nos estudos e na formação da educação especial, o que pode ocasionar um recuo da área (enquanto campo de conhecimento) e pouco desenvolvimento em relação a aspectos que precisam ser superados na educação das pessoas com deficiência.

Constata-se que o professor está inserido num contexto histórico-social determinado por contradições que incidem na expropriação do conhecimento científico, sendo este um dos grandes problemas da educação, pois esta situação resulta no esvaziamento da atividade docente (MARTINS, 2010). Dessa forma, os professores, inclusive aqueles que se dedicam ao AEE, estão expostos às condições degradantes que inviabilizam suas possibilidades efetivas de humanização.

Os pressupostos da Teoria Histórico-Cultural nos indicam que a finalidade da educação da pessoa com deficiência deve voltar-se para a emancipação humana, para a sobreposição dos fatores biológicos, que contém os limites da deficiência, pelos culturais, que proporcionam um desenvolvimento com limites imprevisíveis (VIGOTSKI, 1983). Destacamos, no entanto, que a humanização dos alunos, com ou sem deficiência, depende da mediação das capacidades humanas do professor. Neste sentido, uma preparação emergencial e em larga escala, como assinalam as ações formativas para o trabalho no AEE, constitui-se em uma formação precária que fragiliza a atividade educativa.

Entendemos que a concepção de sujeito com deficiência interfere no trabalho a ser desenvolvido pelo professor, dando-lhe maior ou menor perspectiva frente ao aluno. A superficialidade que envolve a formação a distância não proporciona o conhecimento requerido tendo em vista a atuação no AEE. Dessa forma, corremos o risco de ver a 
inclusão escolar como um projeto educacional posto nas normatizações, divulgado como novo paradigma, mas que não alcança a materialização devido à falta de investimento, de medidas concretas de operacionalização, dentre as quais destacamos a formação docente. Saviani (2009, p.152) ao discutir os aspectos teóricos e históricos da formação de professores no contexto brasileiro, apresenta que "[...] não se pode dizer que a educação especial não tenha sido contemplada na legislação em vigor [...]. No entanto, no que se refere à formação de professores para atuar na educação especial a questão permanece em aberto".

A formação do professor que trabalha no AEE precisa instrumentalizá-lo para que dê conta de várias atividades que exigem conhecimento específico. São diversas as ações que deve desempenhar dentro da cada área que compõe o alunado da SRM. De acordo com Baptista (2011, p.61), a SRM assume um “[...] protagonismo na política educacional brasileira relativa à Educação Especial e à inclusão escolar”. O autor aponta para o fato de que "[...] a pluralidade de ações previstas para o educador nem sempre esteve presente nas propostas que caracterizam as Salas de Recursos." (BAPTISTA, 2011, p.66). Nesse sentido, ainda, comenta que "temos um longo caminho a ser percorrido" e defende que "[...] é necessário reconhecer que, além das diretrizes gerais para a organização das salas de recursos, é fundamental garantir espaço de criação de delineamentos para esse serviço em função de características específicas de cada contexto". (BAPTISTA, 2011, p.71).

A formação de cada profissional é atrelada a efetivação de determinada atividade. No que diz respeito ao professor, de acordo com a prática pretendida faz-se necessária determinada preparação. O exercício das atividades previstas para o AEE denota a necessidade de uma formação que contemple o desenvolvimento de atividades técnicas (como o domínio do Braille, por exemplo), bem como conhecimento teórico e aprofundado acerca do desenvolvimento humano, principalmente da pessoa com deficiência.

Estas constatações nos fazem refletir sobre o quanto é valiosa a produção de conhecimento na área da educação especial e como deve ser consistente a formação do professor do AEE. Além disso, diante da intenção de organizar uma prática escolar que respalde a aprendizagem dos alunos com deficiência, destaca-se a necessidade de opção por referenciais que valorizem o ensino, enquanto condutor do processo educativo.

O professor do AEE tem atribuições diversas em campos de conhecimento específicos o que reitera a necessidade de uma formação teórico-conceitual, pois, o 
alcance de novas formas de conceber e de desenvolver a ação docente não se obtém pela redução dos estudos ao campo prático, imediato; ao contrário, exige estudo teórico e apropriações conceituais por parte do professor.

A formação docente para o AEE, ao comprometer-se com o processo de emancipação humana da pessoa com deficiência, precisa ser constituída por referenciais teóricos que garantam consistência ao saber do professor. Este precisa ter conhecimento acerca do processo de desenvolvimento humano, compreender o sujeito com deficiência sob uma perspectiva que supere a visão biologizante e ter o domínio do processo de ensino dos conteúdos escolares, de modo que possa propor ao aluno mediações, com encaminhamentos metodológicos diferenciados.

\section{O AEE e a educação especial}

Paralelamente a redução da formação docente direcionada para o AEE, a educação especial, como área de pesquisa e campo de conhecimentos, é desvalorizada. Destaca-se um movimento de mudanças que não apenas questiona a educação especial como aponta para a substituição dessa nomenclatura e, possivelmente, dessa área.

O AEE assume tamanha relevância nos documentos divulgados que há indicativos de substituição da educação especial. É o que se percebe no módulo "Atendimento Educacional Especializado: aspectos legais e orientações pedagógicas" (BRASIL, 2007). Em várias ocasiões ao longo do material divulgado pelo Ministério da Educação, há a defesa de que o AEE é equivalente à educação especial, como vemos no argumento abaixo:

[...] louvamos os termos da Constituição Brasileira e das convenções internacionais que nos permitem concluir que o Atendimento Educacional Especializado, destinado a alunos com deficiência, também chamado de Educação Especial, é uma forma válida de tratamento diferenciado (BRASIL, 2007, p.20, grifo nosso).

A proposição do uso da nomenclatura "Atendimento Educacional Especializado" se dá, dentre outros, devido à intenção de defender um novo conceito para a educação especial, pois, segundo o documento já referenciado, “[...] ela sempre foi entendida como capaz de substituir o ensino regular." (BRASIL, 2007, p.28). Acerca dos conhecimentos da educação especial nesse momento histórico, Beyer (2010, p.6) alerta que: 
[...] estamos certamente diante de um movimento internacional de revisão de pressupostos fundamentais da educação especial. As posições neste sentido parecem se alinhar por duas tendências: a) uma abordagem de aproximação de áreas, em que se defende a ideia de relevância das funções da educação especial como elemento de suporte às propostas da educação inclusiva; e b) uma abordagem mais radical de crítica à educação especial, considerando-se que esta, pela sua tradição clínico-terapêutica, tenderia mais a prejudicar do que ajudar as propostas de educação inclusiva.

Temos, entre as distintas opiniões, aquelas que valorizam os conhecimentos já existentes, enquanto há outras que os questionam. O entendimento presente nas divulgações do MEC parece estar mais voltado ao segundo posicionamento, pois há um incentivo à substituição da educação especial pelo AEE, defendendo-se que este contemplaria a proposta inclusiva.

Configura-se, no entanto, a superficialidade dos conhecimentos direcionados à formação do professor para o AEE. Diante da intenção de organizar uma prática educativa que respalde o processo de aprendizagem dos alunos com deficiência, temos a necessidade de aprofundamento nos estudos das suas especificidades e do trabalho que demandam, sem ignorar as discussões correntes na educação de modo geral e nas demais áreas.

Há uma especificidade formada a partir de conhecimentos acumulados no trabalho da educação especial. Por outro lado, não se devem ignorar as discussões correntes na educação de modo geral e nas demais áreas; caso a educação especial se coloque alheia às discussões teóricas que envolvem a educação para a classe popular, fica isolada e perde seu significado. Vigotski (1983) já alertava que a teoria e a prática da educação da criança com atraso profundo, por muito tempo, foram excluídas das vias principais pelas quais transcorria o desenvolvimento da psicologia e da pedagogia gerais, assim estiveram condenadas a um desenvolvimento extremamente lento.

A educação especial, como campo específico de conhecimento, encontra-se em um momento conflituoso, em que até mesmo a sua continuidade é colocada em dúvida. Ao mesmo tempo em que não podemos reter os estudos num campo isolado como se fosse independente dos demais, eliminar os conhecimentos peculiares da educação especial também não nos parece coerente. A formação docente enfrenta a urgência de dar conta de novas questões, assim como esse campo de conhecimento se depara com a 
necessidade de se ressignificar para se atualizar às novas demandas, o que não deveria representar eliminação, mas redimensionamento.

Para que o professor possa desenvolver uma ação pedagógica que contemple as necessidades dos alunos por meio da SRM, precisa ter uma formação que contemple a especificidade desse trabalho. Não basta a conscientização ou a sensibilização do profissional, pois são imprescindíveis os conhecimentos específicos.

Além disso, para que a educação especial não se enclausure nas próprias discussões nem fique restrita a um conjunto de técnicas, faz-se necessária a participação dos profissionais dessa área nas discussões que abordam os determinantes sóciohistóricos da prática educativa desenvolvida no ensino comum. Para que o trabalho pedagógico na SRM contemple as necessidades dos alunos e os eleve culturalmente, o professor precisa de antemão apropriar-se do desenvolvimento cultural que lhe permitirá orientar o processo educativo.

Por meio da educação especial, talvez seja possível buscar vias para superar o barateamento a que foi destinada a formação docente para o AEE. O professor precisa apropriar-se dos conhecimentos gerais que envolvem a educação e dos conhecimentos específicos sem os quais não há viabilidade para o trabalho junto a alunos com deficiência. A especialização não deve significar restrição, mas aprofundamento.

Vale ressaltar que o AEE não substitui a educação especial, pois esta não se resume ao primeiro. A equivalência destes traria uma redução, pois o AEE se organiza em vários serviços que podem ser disponibilizados no próprio ensino regular ou em espaços de apoio em período de contraturno, enquanto que a educação especial, além de ser uma modalidade de ensino, como pressupõe a LDB, é um campo de conhecimento, constituído pela pesquisa e pelo acúmulo de saberes organizado em uma área específica.

\section{Conclusão}

Consideramos, portanto, que a formação dos professores, dentre estes aqueles que se dedicam ao AEE, além de ser insuficiente, é intensamente influenciada, na atualidade, por perspectivas teóricas que coadunam com a negação do conhecimento para a classe popular. A formação a distância associada a desvalorização da educação especial enquanto campo de conhecimento resulta numa preparação docente emergencial que defende para o professor um conhecimento subentendido e imediato 
com graves limitações no que diz respeito à compreensão da realidade e à fundamentação teórico-epistemológica. De acordo com Saviani (2009, p.153):

[...] será necessário instituir um espaço específico para cuidar da formação de professores para essa modalidade de ensino. Do contrário essa área continuará desguarnecida e de nada adiantarão as reiteradas proclamações referentes às virtudes da educação inclusiva que povoam os documentos oficiais e boa parte da literatura educacional nos dias de hoje.

A partir dos materiais normativos, nota-se que há uma centralidade no trabalho da SRM e novas exigências ao professor de educação especial que agora trabalha no AEE. Entendemos, então, que a formação do professor e a constituição de uma especificidade para esse serviço são fatores a serem colocados em discussão. Um avanço para a compreensão do trabalho educativo a ser desenvolvido depende do desenvolvimento de pesquisas que contemplem e subsidiem esta área.

Não obstante os benefícios que o AEE e a SRM possam significar enquanto apoio para a escolarização dos alunos com deficiência, ressaltamos a urgência da organização de uma formação que considere a realidade de cada contexto e ao mesmo tempo proporcione unidade aos fins dessa atividade docente assegurando clareza ao professor sobre o trabalho que deve desempenhar, bem como conhecimento para que o faça. 
ABSTRACT: This paper aims to present partial results of desk research and literature on the Educational Service Specialist - ESA held at Room Multifunctional Resources. We seek to identify the duties of teacher training ESA and directed this professional. From 2008, this service is made evident in the normative centrality and features as support for the inclusion of students with disabilities in regular schools. We believe that training directed to the teacher as a way to update it to work the ESA, is still insufficient. Furthermore, we found that, just as with the other teachers, the training has characteristics that denote superficiality, with membership mode of distance learning. Having as parameter the Cultural-Historical Theory, we understand the importance of investment in consistent training that instrumentalizes teacher, besides from this benchmark highlight the importance of teaching action while mediation to the educational process of the students.

KEY WORDS: Educational service specialist. Resource room multifunctional. Assignments teacher. Teacher training.

\section{REFERÊNCIAS}

BAPTISTA, C. R. Ação pedagógica e educação especial: a Sala de recursos como prioridade na oferta de serviços especializados. Revista Brasileira de Educação Especial, Marília, v.17, p.59-76, mai./ago. 2011.

BEYER, H. O. Inclusão e avaliação na escola. 3.ed. Porto Alegre: Mediação, 2010.

BRASIL. Ministério da Educação. Atendimento educacional especializado - aspectos legais e orientações pedagógicas. Brasília: MEC/SEESP, 2007.

Política Nacional de Educação Especial na perspectiva da Educação Inclusiva. Brasília: MEC/SEESP, 2008.

Resolução n⿳0 04, de 02 de outubro de 2009. Institui as Diretrizes operacionais para o atendimento educacional especializado na educação básica - Modalidade educação especial. Brasília: Conselho Nacional de Educação, 2009.

Presidência da República. Decreto no 7.611 , de 17 de novembro de 2011. Dispõe sobre a educação especial, o atendimento educacional especializado e dá outras providências. Brasília: Senado Federal, 2011.

DUARTE, N. Vigotski e o "aprender a aprender": crítica às apropriações neoliberais e pós-modernas da teoria vigotskiana. 4.ed. Campinas: Autores Associados, 2006.

LEONTIEV, A. O desenvolvimento do psiquismo. Lisboa: Horizonte, 1978.

MARTINS, L. M. O legado do século XX para a formação de professores. In: MARTINS, L. M.; DUARTE, N. (Org.). Formação de professores: limites contemporâneos e alternativas necessárias. São Paulo: Cultura Acadêmica, 2010. p.13$32 . \quad$ Disponível em: <http://xa.yimg.com/kq/groups/17003889/409437426/name/\%7BF8758FD2-BCCA- 
496B-A3C7-616A2EE10440\%7D_Formacao_de_professores-digital.pdf>. Acesso em: $12 \mathrm{dez} 2012$.

SAVIANI, D. Formação de professores: aspectos históricos e teóricos do problema no contexto brasileiro. Revista Brasileira de Educação, Rio de Janeiro, v.14 n.40, jan./abr. 2009.

VIGOTSKI, L. S. Obras completas. Tomo V - Fundamentos de defectología. Cuba: Editorial Pueblo Educación, 1983. 